Behavioural Processes

May 2016, Volume 126, Pages 113-120

http://dx.doi.org/10.1016/i.beproc.2016.03.008

http://archimer.ifremer.fr/doc/00319/43049/

(c) 2016 Elsevier B.V. All rights reserved.

\title{
The shy prefer familiar congeners
}

\author{
Benhaïm David ${ }^{1,{ }^{*}}$, Ferrari Sebastien ${ }^{2}$, Chatain Beatrice ${ }^{3}$, Bégout Marie-Laure ${ }^{2}$
}

${ }^{1}$ Cnam- Intechmer, BP 324, 50103 Cherbourg cedex, France

2 Ifremer, Place Gaby Coll, F-17137 L'Houmeau, France

${ }^{3}$ Ifremer, Station Expérimentale d'Aquaculture, Chemin de Maguelone, F-34250 Palavas-Les-Flots, France

*Corresponding author : David Benhaïm, email address : david.benhaim@cnam.fr

\begin{abstract}
:
The shy-bold continuum is both a fundamental aspect of human behavior and a relatively stable behavioral trait for many other species. Here we assessed whether shy individuals prefer familiar congeners, taking the European sea bass, a recently domesticated fish showing similar behavioral responses to wild fish, as a model to better understand the inter-individual variability in social behavior previously observed in this species. In the wild, the link between familiarity i.e. the preference of fish for familiar congeners and boldness could be part of the mechanism underlying shoaling formation in fish. Thirty fish were individually tested in a device designed to assess the preference for a familiar vs. an unfamiliar congener on the basis of visual cues only. An open field test (OFT) with shelter was performed on the same fish 32 days later to assess the boldness of each individual. Variables of interest included the proportion of time spent in the shelter, border and center zone of the arena and variables of activity. Variables measured in OFT were collapsed into first principal component scores using Principal Components Analysis (PCA) which allowed characterizing a shy-bold continuum. Time spent near the familiar congener was negatively correlated with boldness i.e. shy individuals spent most of the time near the familiar congener. We discuss the relevance of these findings to the understanding of the behavior of European sea bass and suggest that the link between familiarity and shyness is a general aspect of both animal and human behavior.
\end{abstract}

\section{Highlights}

- We assessed sea bass preference for familiar congener. We assessed sea bass boldness. Shy individuals prefer to spend time near familiar congeners. We suggest the link between familiarity and shyness is a general aspect of both animal and human behaviour.

Keywords : familiarity, personality, open field, social behavior, swimming activity, shyness, shoaling behavior, visual cue 


\section{INTRODUCTION}

31 The shy-bold continuum is both a fundamental aspect of human behavior and a relatively stable behavioral component for many other species (Wilson, 1994). Coleman and Wilson (1998) suggested that shyness and boldness may be context specific, but they also form one of the five axes of animal personality defined as a correlated set of individual behavioral and physiological characteristics that are consistent over time and across situations (Koolhaas et al., 1999). These five axes are: boldness (response to potentially risky situations), activity, exploration (response to novel situations), aggressiveness and sociability. Correlations between different personality traits may exist, leading to the formation of a behavioral syndrome (Sih et al., 2004). The shy-bold continuum has been studied in numerous vertebrates (Benus, 1991; Boon, 2007; Careau, 2010; Verbeek et al., 1994), including teleosts e.g. the rainbow trout Oncorhynchus mykiss (Øverli et al., 2006; Sneddon, 2003) and the European sea bass (Ferrari et al., 2014; Ferrari et al., 2015) as well as in invertebrates (Briffa and Greenaway, 2011).

In fish species, boldness is usually associated with a proactive strategy whereas shyness is associated with a reactive strategy. Proactive animals tend to engage in active avoidance or cope with stressful stimuli (Koolhaas, 2008; Koolhaas et al., 1999) through a "fight or flight" response contrary to reactive ones which display a passive behavior through a "freeze and hide” response. Bold fish take more risks and explore their environment faster (less cautiously) when exposed to novelty (MacKenzie, 2009; Øverli et al., 2006), and they are more aggressive, dominant (Castanheira et al., 2013; Øverli et al., 2004), and less flexible 51 than shy fish i.e. they show a lower variability in their behavioral responses with 52 environmental changes (Ruiz-Gomez, 2011). By contrast, shy individuals tend to be risk averse and are generally neophobic, show higher behavioral flexibility and are more 
responsive to their environment (Sneddon, 2003), and more sociable than bold individuals (Ward et al., 2004). Intermediate fish are in the middle of these two extremes.

In the wild, gregarious species form shoals that represent non-random assemblages according to species, size, parasite load and familiarity i.e. individuals prefer to join groups with which they have had a previous experience (Griffiths, 2003; Griffiths and Ward, 2007; Hoare et al., 2000; Krause et al., 1996; Krause and Ruxton, 2002; Pitcher and Parrish, 1993). Shoaling behavior in fish is also an important antipredator strategy (Magurran, 1990; Pitcher and Parrish, 1993). Familiarity maximizes the benefits of grouping and mediates association decisions in shoaling species (Griffiths and Ward, 2007). However, the importance of social dynamic and fidelity of fish shoals in the wild remains unclear because these variables are difficult to monitor (Helfman, 1984; Hilborn, 1991; Hoare et al., 2000; Svensson et al., 2000). Furthermore, the decision to shoal strongly depends on the context encountered by the fish e.g. European minnows Phoxinus phoxinus shoal to obtain shelter, but only when there is insufficient physical structure available (Orpwood et al., 2008). Thus, one could expect that the preference for familiar fish increases under the threat of predation, but several studies have found that the preference of fish for familiar individuals is not affected by the appearance of a model predator (Brown, 2002; Griffiths, 1997). This suggests that fish have adapted to maintain a consistent preference for familiar congeners in habitats where they are often exposed to predators.

It is well known that boldness can have potential fitness consequences by influencing many traits including mate choice (Godin and Dugatkin, 1996), parental care (Budaev, 1999), reproductive success (Armitage and Van Vuren, 2003) and anti-predator behavior (Réale and Festa-Bianchet, 2003), but the link between familiarity, i.e. the preference for familiar congeners, and boldness as a mechanism underlying shoaling formation in fish, has not yet been addressed. 
The aim of the current study was to assess whether shy individuals prefer familiar congeners, taking the European sea bass as a model. This species was recently domesticated and shows high interindividual behavioral variability, with some domesticated individuals presenting similar responses to wild fish (Benhaïm et al., 2012). In a previous study (Benhaïm et al., 2013a) comparing wild and domesticated juvenile sea bass, we found that fish were similarly attracted to unfamiliar congeners, on the basis of visual cues alone. However, some individuals (both wild and domesticated) spent most of their time on the opposite side (empty compartment) of the unfamiliar congener. Here, we used a preference test for a familiar vs. unfamiliar congener and a boldness test to examine whether this inter-individual variability could be explained by a link between the shy-bold continuum and familiarity.

\section{METHODS}

\section{Experimental animals and housing conditions}

Two separate batches of sea bass were hatched at the Aquanord SA farm (France). On November $11^{\text {th }} 2011$, when the fish were 3 days old, they were transferred to the experimental station of INTECHMER (Cherbourg) and grown in a recirculated system. All parameters were set according to the protocol used by Aquanord hatchery.

Fish (about 300 individuals per batch) were later grown in an open water system (i.e. physicochemical parameters resembling natural conditions) in two separate $2 \mathrm{~m}^{3}$ tanks until the beginning of this experiment which started on March $22^{\text {nd }} 2014$. At this time, the fish were 865 days old.

Fish from both tanks were anesthetized with benzocaine (200 ppm) and 40 individuals from each tank were selected based on previous biometric data. Total length (mean \pm SD) was 13.9 $\pm 0.9 \mathrm{~cm}$ in the first tank and $13.8 \pm 0.8 \mathrm{~cm}$ in the second; weight was $28.4 \pm 3.2 \mathrm{~g}$ in the first tank and $28.1 \pm 2.8 \mathrm{~g}$ in the second. All the selected individuals were PIT-tagged (Iso, $9 \times 1.4$ 
$\mathrm{mm}$ ) on the same day by inserting a tag horizontally just behind the head to prevent any change of position after implantation.

To optimize the familiarization process between individuals, the two groups of 40 selected individuals were placed in two $200 \mathrm{~L}$ tanks for 75 days. The tanks were provided with water

108 from a recirculated system. During this period, the light regime was a 16:8 LD cycle (light 109 onset at 06:00 U.T. +1 ). In both tanks, temperature, salinity and oxygen level were (Mean \pm $110 \mathrm{SD}), 18.5 \pm 0.3^{\circ} \mathrm{C}, 35.0 \pm 0.0 \mathrm{~g} \mathrm{~L}^{-1}, 6.5 \pm 0.2 \mathrm{mg} \mathrm{L}^{-1}$, respectively. Fish were fed manually 111 until satiation three times daily with a commercial diet (Neo Grower Extra Marin, 4 mm, Le 112 Gouessant, France).

Observation room

115 Observations were made in a dedicated room. All experiments were video recorded at 25 116 frames per second (Ethovision XT recording, Noldus, the Netherlands; camera Ikegami 117 CD48E; 2.8 - 12 mm Computar ${ }^{\circledR}$ lens equipped with an IR filter positioned at $180 \mathrm{~cm}$ above 118 the water surface). An infrared casing (1x1 m, Noldus, The Netherlands) was placed under the 119 apparatus used in this experiment to enable the recording of videos at low light intensity and 120 to improve video analysis. Two $60 \mathrm{~W}$ light bulbs were horizontally placed on walls located on 121 the left and right sides of the infrared casing. They were located $180 \mathrm{~cm}$ above the infrared casing and provided an indirect and homogenous lighting on the apparatus. The light intensity 123 measured at the water surface was 100 Lux.

\section{Familiarity test}

126 Individuals were tested one by one in a device (90*40 cm with a water height of $15 \mathrm{~cm})$

127 constructed from opaque white plastic and transparent Plexiglas ${ }^{\circledR}$ (Fig. 1). The start box (40 x $12820 \mathrm{~cm}$ ) was separated from the rest of the device by a removable transparent wall. The end of 
129 the device (located in front of the start box) was occupied by two separate compartments 130 (precluding olfactory cues) with one transparent wall. These compartments, continuously 131 supplied with air (air pump), were used to place a congener that was either familiar or 132 unfamiliar to the test individual. The familiarity test was therefore based on visual cues that 133 have been shown to underpin individual recognition in a variety of species (Balshine-Earn et 134 al., 1998; Fricke, 1973; Hert, 1985). Shortly before observations, the device was filled with 135 water, the level of which was maintained at $15 \mathrm{~cm}$. Temperature, salinity and oxygen level 136 were verified before and after the end of observations performed on each fish and were 137 respectively $18.4 \pm 0.5^{\circ} \mathrm{C}, 35.0 \pm 0.0 \mathrm{~g} \mathrm{~L}^{-1}, 6.6 \pm 1.3 \mathrm{mg} \mathrm{L}^{-1}$ before and $18.4 \pm 0.3^{\circ} \mathrm{C}, 35.0 \pm$ $1380.0 \mathrm{~g} \mathrm{~L}^{-1}, 6.6 \pm 1.2 \mathrm{mg} \mathrm{L}^{-1}$ after.

139 Before the beginning of observations, the position of the unfamiliar or familiar congener on 140 the left or right side inside the independent boxes located at the end of the device was 141 randomly determined for each individual. This device shape was used instead of a T-maze to 142 minimize potential bias related to side-turning preference. The first tested fish was gently 143 collected from the tank using a net and immediately placed inside a bucket closed by a cover 144 and then placed in the start-box. After a 10 min acclimatization period, the transparent wall 145 was removed and the video capture started. The device was filmed for $30 \mathrm{~min}$. The 146 experiment was carried out when the fish were 939 days old and three days were required to 147 test all individuals $(\mathrm{N}=30)$. The water was entirely renewed every two hours. The unfamiliar 148 and familiar fish used as the attractors were changed every two hours to minimize the stress of 149 confinement and handling (10 individuals from each category were used for the experiment).

150 Before being returned to their initial tank, fish were anesthetized and their length and weight 151 were measured. 
152 The video recordings were analyzed using EthoVision XT software (Noldus, The

153 Netherlands), which allowed six virtual zones to be defined in the device (Fig. 1) and to track

154 the swimming behavior of the fish.

155 Different variables of interest (position preference or activity) were chosen to analyze the 156 behavior of the fish:

157 -The proportion of time spent in each of the six defined zones (\%): Start-Box in front of the 158 familiar (Start-Fam) or the unfamiliar congener (Start-UnFam), Pre-Familiar and Pre159 Unfamiliar located between Start-Fam/Start-Unfam and Fam/UnFam (Pre-Fam and Pre160 Unfam), zone near the familiar congener (Fam), zone near the unfamiliar congener (UnFam). 161 -The distance traveled by each fish in the device (Dtot in $\mathrm{mm}$ ).

162 -The velocity mean expressed in body length per second ( $\mathrm{Vel}$ in $\mathrm{BL} \mathrm{s}{ }^{-1}$ ).

163 The last two variables quantified the fish swimming activity level in the device.

164 -The absolute angular velocity of the fish expressed in degree per second (Vang in ${ }^{\circ} \mathrm{s}^{-1}$ ), 165 which was calculated by the software as follows:

166 Vang $_{n}=$ RTA $_{n} / t_{n}-t_{n-1}$ where RTA $A_{n}$ is the relative turn angle for the sample $n$, and $t_{n}-t_{n-1}$ is 167 the time difference between the current and previous sample. The rate of change in direction 168 was unsigned. The turn angle was calculated as the difference between two subsequent values 169 for the direction of the head. This variable was an indicator of the amount of turning per unit 170 time and quantified the swimming path complexity, high Vang values being linked to higher 171 level of vigilance (Benhaïm et al., 2012).

Boldness test in the open field apparatus

175 An open field test (OFT) with shelter was performed when the fish were 973 days old i.e. 32 176 days after the familiarity test to ensure the fish had recovered from the first test. Among 
numerous behavioral tests used to assess the shyness-boldness axis, open field tests (Budaev 1999, 1999; Yoshida 2005) are widely used and was chosen in this case because it has been successfully applied in previous studies on sea bass (Ferrari et al., 2014). The open field (90* $40 \mathrm{~cm}$ with a water height of $15 \mathrm{~cm}$, Fig. 2) contained a shelter (opaque PVC box $20 * 20 *$ $20 \mathrm{~cm}$ closed by a vertically sliding opaque trapdoor) placed in one corner and was divided into four virtual zones using the software EthoVision XT: Entry, Pre-shelter, Border and Center. The center zone was considered a risky area because thigmotaxis (staying close to the walls of an arena) is a common measure indicative of a high degree of shyness in such an apparatus (Dahlbom, 2011; Maximino, 2010). Selected fish ( $\mathrm{N=30)}$ were individually placed in the shelter. After a $10 \mathrm{~min}$ acclimatization period, the door was gently opened. If the individual did not leave the shelter within 20 minutes following the acclimatization time, the experiment was stopped and a latency of 1200 seconds was attributed. . Before being returned to their initial tank, fish were anesthetized and their length and weight were measured.

Variables of interest were extracted with Ethovision XT and were as follows:

- The latency of each individual to emerge from the shelter (Lat in s), the proportion of time (\%) respectively spent in the shelter (Shelter), the center zone (Center), the border zone (Border), the pre-shelter zone (Pre-Shelter), and at the entrance of the shelter (Entry).

- The mean distance from the shelter (DtoShelter in $\mathrm{cm}$ ) and the number of returns to the shelter (FreqShelter).

- The distance travelled by each fish in the device (Dtot in $\mathrm{mm}$ ), the absolute angular velocity of the fish expressed in degrees per second (Vang in ${ }^{\circ} \mathrm{s}^{-1}$ ), and its mean velocity expressed in body length per second (Vel in $\mathrm{BL} \mathrm{s}^{-1}$ ). 
In both experiments, the spatial distribution of fish was analyzed using parametric analysis of

203 variances (ANOVA) with zone as an independent factor after verification of distribution normality and homoscedasticity (Dagnélie 1975). If the data did not fulfill these requirements, non-parametric Kruskall-Wallis tests were used. Significant ANOVA were followed by a posthoc multiple comparison test (Newman-Keuls) and significant Kruskall-Wallis tests by rank-based multiple comparisons.

All the variables measured in OFT were collapsed into first principal component scores using Principal Components Analysis (PCA). A correlation matrix was used to verify multicollinearity, i.e., to identify variables that did not correlate with any other variable, or correlate very highly $(r=0.9)$ with one or more variables. Those latter variables were removed from downstream analyses. The remaining selected variables used for the PCA were: Shelter, Center, Border, Pre-Shelter, Entry, DtoShelter and FreqShelter. Each individual fish was then affected a PC1 score later used in cross-context analysis. The too small number of variables issued by the familiarity test prevented running PCA analysis.

Associations within tests were assessed by non-parametric Spearman’s rank order correlation. The correlations within tests were corrected using the Bonferroni method with $n=9$ for the familiarity test and $n=11$ tests for the OFT, thresholds for significance being 0.0055 and 0.0045, respectively. For cross-context analysis (between tests), we analyzed the correlation between individual values for either the proportion of time spent in the Fam zone or UnFam zone and PC1 individual scores from OFT using Pearson's correlation coefficient.

\section{RESULTS}


225

226

227

228

229

230

231

232

233

234

235

236

237

238

239

240

241

242

243

244

During the experiment, no mortality was recorded and all fish grew similarly: Body weight and Total length were (Mean \pm SD) $32.6 \pm 3.2 \mathrm{~g}$ and $14.3 \pm 0.7 \mathrm{~cm}$, respectively, after the familiarity test, and $38.0 \pm 4.2 \mathrm{~g}$ and $15.1 \pm 0.7 \mathrm{~cm}$, respectively after the open field test.

\section{Familiarity test}

All the fish tested left the start zone after the wall was removed, i.e. none of the fish spent $100 \%$ of the time in the Start-Fam or Start-UnFam zone.

Fish spent most of the time in the Fam zone (mean \pm SE, $28.9 \pm 6.7 \%$, Fig. 3) but also some time in the UnFam, Start-Fam and Start-UnFam zones $(19.3 \pm 5.2 \%, 18.3 \pm 5.7 \%$ and $19.3 \pm$ $6.4 \%$, respectively). The time spent in the device was not randomly distributed between zones (ANOVA: F5, $180=2.7, p=0.02$ ), with fish spending significantly more time in the Fam, UnFam and Start-Fam zones than in the Pre-Fam and Pre-UnFam zones (Fig. 3). There was high inter-individual variability with 11 individuals spending most of the time in the Fam zone, six in the UnFam zone, four in the Start-UnFam zone, five in the Start-Fam zone, two in the Pre-Fam zone, and two in the Pre-UnFam zone. The proportion of time spent in the Fam zone was significantly correlated with Vang (Spearman rank correlation: $r s=-0.58, \mathrm{~N}=$ $30, p=0.002)$ and with $\operatorname{Vel}(r s=0.67, \mathrm{~N}=30, p=0.0002)$.

\section{Open field test}

Six individuals (out of 30) spent all the time inside the shelter. Including those fish with a latency of 1200 s, the mean latency to emerge from the Shelter was $460.3 \pm 88.1$ s. Fish spent most of the time in the Shelter and Border zones (56.1 $\pm 7.9 \%$ and $24.4 \pm 6.0 \%$, respectively,

Fig. 4). The proportion of time spent in the apparatus significantly differed between zones (Kruskal-Wallis test: H4,150 $=30.05, p<0.0001$ ), with fish spending more time in the Shelter zone than in the Center, Pre-shelter and Entry zones (Fig. 4). There was a significant 
correlation between Dtot and the proportion of time spent in Border or Shelter zones $(r=$ 0.46, $\mathrm{N}=30, p=0.04$, and $r s=-0.49, \mathrm{~N}=30, p=0.03$, respectively). Dtot and DtoShelter were correlated ( $r=0.57, \mathrm{~N}=30, p=0.01$ ), and Vang and FreqShelter were inversely correlated $(r=-0.52, \mathrm{~N}=30, p=0.02)$. Finally, the proportion of time spent in Shelter was strongly inversely correlated with that spent in Border zone $(r=-0.98, \mathrm{~N}=30, p<0.0001)$. The first component (PC1) explained 44\% of the variation in the data (loadings: Shelter = 0.97. Border $=0.85$. Center $=-0.55$. PreShelter $=0.29$. Entry $=0.36$. FreqShelter $=0.16$. DtoShelter $=0.93)$ ). PC1 was therefore related to two extremes: the negative pole to high values of Shelter (contribution to the first component was 0.31 and the correlation was 0.974), the positive one to high values of Border and DtoShelter (contributions to the first component were 0.23 and 0.28 and the correlations were 0.85 and 0.93 respectively). PC1 represented therefore a gradient from shy (high values of shelter) to bold individuals (high values of Border and DtoShelter).

\section{Links between the Familiarity and open field test results}

The proportion of time spent in the Fam zone was negatively correlated with PC1 individual scores ( $r=-0.41, \mathrm{~N}=30, p=0.04$, Fig. 5). Proportion of time spent in the UnFam zone was not significantly correlated with PC1 individual scores $(r=-0.17, \mathrm{~N}=30, p=0.41)$.

\section{DISCUSSION}

The aim of this study was to assess whether shy individuals prefer congeners with whom they are familiar, taking the European sea bass, a recently domesticated fish species, as a model. We determined whether fish were attracted to a familiar or an unfamiliar congener and then assessed boldness using an open field test. 
274 Fish tended to spend more time in the zone near the familiar congener but this was not

275 significantly different from that spent near the unfamiliar congener. This is likely due to high

276 variability between individuals that reduced the statistical power of the analysis. This

277 variability has already been observed under similar situations where we showed that some

278 individuals voluntarily avoided the zone located near an unfamiliar congener, preferring

279 instead to spend time in the opposite zone near an empty compartment, whereas others spent

280 most of the time in the start box (Benhaïm et al., 2013a). Overall, fish spent almost 60\% of

281 the time near a familiar or unfamiliar congener, possibly because social or gregarious species

282 may greatly benefit from social interactions regulating the stress response, especially when

283 placed in a novel and therefore stressful environment (Allen et al., 2009). Indeed, group

284 behavior promotes growth as a result of social facilitation (Peuhkuri et al., 1995; Stirling,

285 1977) and limits the risk of predation (Roberts, 1996). Vigilance is much lower when the

286 distance between neighbors is small, because information about whether other group members

287 have detected a predator is easier to obtain from close individuals than from distant ones

288 (Pöysä, 1994). Such gregarious behavior is widespread among fishes, and swarms, flocks,

289 herds-group formation are also a widespread phenomenon in many different animal species

290 populations (Krause and Ruxton, 2002). Further, the time spent near the familiar congener

291 was positively correlated with velocity and negatively correlated with angular velocity.

292 Velocity and angular velocity are linked to a high level of visual interaction between the

293 tested fish and the familiar congener through the transparent wall and a lower level of

294 vigilance as already shown in previous studies (Benhaïm et al., 2013a).

295 Several theories can explain the observed variability in behavior. First, the decision to shoal

296 strongly depends on the context encountered by the fish, in accordance with Hamilton’s

297 theory of the selfish herd (Hamilton, 1971). Fish choosing not to shoal with familiar or

298 unfamiliar congeners may be considered subordinate. Indeed, staying alone is the best 
strategy for subordinates (Pitcher and Parrish, 1993), because it protects them from suffering injuries in an escalated contest (Hilborn, 1991). Second, congener avoidance or preference for the familiar or the unfamiliar congener may also be linked to particular behavioral traits such as boldness, as discussed below.

The proportion of time spent in the shelter, which provides a relevant indication of boldness, varied substantially between individuals, consistent with previous studies (Biro and Stamps 2008; Brown, 2007; Budaev 1999; Eriksson, 2010; Fraser, 2001). When the fish left the shelter, they spent most of the time in the Border zone and only a very short time in the Center zone. The proportion of time spent in the border zone was negatively correlated with the proportion of time spent in the shelter, consistent with a previous study on the same species under similar conditions (Ferrari et al., 2014). Experiments in such devices involve handling and isolating the fish, which is clearly stressful for all individuals regardless of their boldness level, as already shown by previous studies on Zebrafish, Danio rerio (Blaser and Vira, 2014) and sea bass (Benhaïm et al., 2013a; 2013b; 2013c). This may explain why all individuals preferred to swim in the border zone, because this area is perceived by the fish to be safer than the central zone. Unsurprisingly, the total distance traveled in the device was positively correlated with the time spent in the border zone and the distance to shelter which showed that the fish were not motionless when they left the shelter as already observed in a previous study (Ferrari et al., 2014). The PCA approach allowed us to identify a clear ShelterBorder/Distance to shelter axis which can be used as a proxy for evaluating the shy-bold continuum in sea bass (Ferrari et al., 2015).

Linking the results of the familiarity and open field tests, we found a strong negative correlation between the proportion of time spent near the familiar congener and boldness. Fish 
which spent more time inside than outside the Shelter (i.e. shy fish) preferred to stay near the

325 familiar congener. On the contrary, bold fish did not show any preference for the familiar or unfamiliar congener i.e. they were equally attracted to both congeners. Shy fish tend to be risk averse (Wilson, 1994); which is supported by our work, as they preferred to shoal with familiar congeners with whom they have established a stable relationship over a long period of time without encountering major aggression or other incidents that they were unable to cope with previously. However, our study did not show any obvious avoidance of unfamiliar congeners in shy individuals. Bold fish have been shown to take more risks and explore their environment less cautiously when exposed to novelty (Øverli et al., 2006; MacKenzie et al., 2009), which may explain why they spent the same amount of time near familiar and unfamiliar congeners. We hypothesize that these individual differences in behavior could be related to personality traits even though the consistency over time was not tested in the present study. The repeatability of personality tests is still a major concern in sea bass as well as in other animal species. For example, Bell et al. (2009) reported that repeatability was greater for experiments separated by short intervals than for those separated by longer intervals. Further, a previous work on sea bass showed the lack of consistency over time in 340 the results obtained for individual-based tests (OFT was however not used in this experiment) that is likely due to the stress induced by repeated trials (Ferrari et al., 2015). The results of 342 these repeated tests could also be biased by the high memory and learning abilities observed 343 in this species, defined as a change of behavior with experience (Dill, 1983).

344 The familiar congener preference could also be related to sociability and the link between 345 shyness and the familiar congener preference could be indicative of a behavioral syndrome in 346 sea bass. As already shown by previous studies on birds, shy individuals tend to be more 347 sociable than bold individuals (Verbeek et al., 1994). The potential existence of behavioral 348 syndromes in sea bass has already been suggested in previous work e.g. individuals with a 
passive response during a restraint test tended to be shyer during an open field test (Ferrari et

350 al., 2014). The present study and a previous one on the same species (Benhaïm et al., 2013a)

351 showing that individuals were attracted to unfamiliar congeners when they had no other

352 choice apart from an empty compartment in a T-maze, enable a better understanding of the

353 decision process in sea bass. If they have the choice, bold individuals will spend the same

354 amount of time near familiar and unfamiliar congeners whereas shy individuals will spend

355 more time near the familiar congener. If they have no choice, both bold and shy individuals

356 will spend more time near the congener whether familiar or not. Finally, because our study

357 showed a preference in shy individuals to stay near the familiar congener, it also confirms that

358 sea bass are able to discriminate familiarity on the basis of visual cues alone as already shown

359 on the same or different species (Brown, 2002; Brown and Colgan, 1986; Di-Poï, 2008;

360 Griffiths, 1997; Waas and Colgan, 1994)

362 When assessing the significance of these results in the wild, it is important to consider that sea 363 bass pelagic eggs are largely dispersed by estuarine currents and individuals are gregarious 364 especially at the juvenile stage (Barnabé, 1978); however, little is known about dispersal, 365 shoal site fidelity and shoal fidelity in wild sea bass. Some authors however mentioned post366 larvae and fry congregating in upper estuaries, creeks and harbors i.e., a few dozen to many 367 thousands remaining in distinct groups for several years at a time (Aprahamian and Barr, 368 1985; Claridge and Potter, 1984; Dando and Demir, 1985; Kelley, 1988). Furthermore, 369 shoaling behavior is known to be generated by visually stimulating attractions between 370 individuals but it could also involve the recognition of familiar congeners on the basis of 371 visual cues. 
372 Further research is needed to confirm that the significant individual differences and the

373 significant correlation between familiarity and shyness in our sea bass population point to 374 personality traits differences and behavioral syndromes.

375

Subject to the confirmations of these conditions, our results may apply to many other species, including humans. Indeed, personality has been identified in a broad array of species and some aspects of personality show considerable cross-species generality (Capitanio, 1999; Gosling, 2001; Gosling and John, 1999; Seyfarth et al., 2012). Neuman (2014) argues for a cognitive-biological theory of personality stating that the common denominator of various personality theories are neural systems of threat/trust management and their emotional, cognitive, and behavioral dimensions. The world is a challenging place and both human and non-human organisms have to cope with many threats (Neuman, 2014). Variability of personality traits may result from the dynamics of evolutionary game theory that reach a particular optimum of trade-offs (Costa, 1980). To cope with a stressful environment, we found that shy fish chose to join the familiar congener on the basis of visual cues only, much like human newborn babies who prefer their parents' and other familiar voices over those of strangers (Zajonc, 1968), or shy adults who prefer to avoid meeting strangers (Crozier, 2001). Individual recognition and experience of past encounters strongly influences social behavior (Hinde, 1985) i.e. we act differently in the company of somebody we know than in that of a person we meet for the first time.

In conclusion, our study reveals an interesting link between familiarity and shyness that may be a general aspect of both animal and human behavior. Further research is needed to confirm this hypothesis. Within sea bass species, it would be useful to understand better the link between boldness and shoal preference in different environmental and social contexts i.e. trade-offs that individuals with different behavioral characteristics face when considering competition for foraging and predation risk. Behavioral studies on different social species 
including humans are required to verify the generality of the link between familiarity and shyness.

400

401

402

403

404

405

406

407

408

409

410

411

412

413

414

415

416

417

418

419

420

421

422

423

424

425

426

427

428

429

430

431

432

433

434

\section{Ethical Statement}

This study was conducted under the approval of the Animal Care Committee of France under the official licence of M.L. Bégout (17-010).

\section{Acknowledgements}

We are grateful to Aquanord for providing the animals. We also thank Romain Theysset, Louise Vernier and Margaux Denamiel for technical help.

\section{References}

Allen, P.J., Barth, C.C., Peake, S.J., Abrahams, M.V. and Anderson, W.G. 2009. Cohesive social behaviour shortens the stress response: the effects of conspecifics on the stress response in lake sturgeon Acipenser fulvescens. J. Fish Biol. 74, 90-104.

Aprahamian, M.W. and Barr, C.D. 1985. The growth, abundance and diet of 0-group sea bass, Dicentrarchus labrax, from the Severn Estuary. J. Mar. Biol. Ass. U.K. 65, 169-180.

Armitage, R.B. and Van Vuren, D.H. 2003. Individual differences and reproductive success in yellow-bellied marmots. Ecology and Evolution 15, 207-233.

Balshine-Earn , S., Neat, F.C., Reid, H. and Taborsky, M. 1998. "Paying to stay or paying to breed? Field evidence for direct benefits of helping behavior in a cooperatively breeding fish". Behav. Ecol. 9, 432-438

Barnabé, G. 1978. Etude dans le milieu naturel et en captivité de l'écoéthologie du Loup Dicentrarchus labrax (L.) (Poisson Serranidae) à l'aide de nouvelles techniques. Annales Sciences Naturelles, Zoologie, Paris, 12e série, 20, 423-502.

Bell, A.M., Hankison, S.J. and Laskowski, K., L. 2009. The repeatability of behaviour : a meta-analysis. Elsevier, Amsterdam, PAYS-BAS.

Benhaïm, D., Bégout, M.-L. and Chatain, B. 2013. Unfamiliar congener used as a visual attractor in wild caught and domesticated sea bass (Dicentrarchus labrax) placed in a T-maze. Journal of Aquaculture Research Development 4, 169-175.

Benhaïm, D., Bégout, M.-L., Péan, S., Manca, M., Prunet, P. and Chatain, B. 2013. Impact of a plant-based diet on behavioural and physiological traits in sea bass (Dicentrarchus labrax). Aquat. Living Resour. 26, 121-131 
Benhaïm, D., Bégout, M.-L., Lucas, G. and Chatain, B. 2013. First insight into exploration and cognition in wild caught and domesticated sea bass (Dicentrarchus labrax) in a maze. PLoS ONE 8(6), e65872.

Benhaïm, D., Péan, S., Lucas, G., Blanc, N., Chatain, B. and Bégout, M.-L. 2012. Early life behavioural differences in wild caught and domesticated sea bass (Dicentrarchus labrax). Appl. Anim. Behav. 141, 79-90.

Benus, R.F., Bohus, B., Koolhaas, J.M., Oortmerssen, G.A. 1991. Heritable variation for aggression as a reflection of individual coping strategies. Experientia 47, 1008-1019.

Biro, P.A. and Stamps, J.A. 2008. Are animal personality traits linked to life-history productivity? Trends Ecol. Evol. 23, 361-368.

Blaser, R.E. and Vira, D.G. 2014. Experiments on learning in zebrafish (Danio rerio): A promising model of neurocognitive function. Neurosci. Biobehav. Rev. 42, 224-231.

Boon, A.K., Réale, D., Boutin, S.,. 2007. The interaction between personality, offspring fitness and food abundance in North American red squirrels. Ecology Letters 10, 1094-1104.

Briffa, M. and Greenaway, J. 2011. High in situ repeatability of behaviour indicates animal personality in the Beadlet anemone Actinia equina (Cnidaria). PLoS ONE 6, e21963.

Brown, C., Jones, F. and Braithwaite, V.A. 2007. Correlation between boldness and body mass in natural populations of the poeciliid Brachyrhaphis episcopi. J. Fish Biol. 71, 1590-1601.

Brown, C. 2002. Do female rainbowfish (Melanotaenia spp.) prefer to shoal with familiar individuals under predation pressure? J. Ethol. 20, 89-94.

Brown, J.A. and Colgan, P.W. 1986. Individual and species recognition in centrarchid fishes: evidence and hypotheses. Behav. Ecol. Sociobiol. 19, 373-379.

Budaev, S.V., Zworykin, D.D., Mochek, A.D.,. 1999. Individual differences in parental care and behaviour profile in the convict cichlid: a correlation study. Anim. Behav. 58, 195-202.

Capitanio, J.P. 1999. Personality dimensions in adult male rhesus macaques: Prediction of behaviors across time and situation. Am. J. Primatol. 47, 299-320.

Careau, V., Réale, D., Humphries, M.M., Thomas, D.W. 2010. The pace of life under artificial selection: Personality, energy expenditure, and longevity are correlated in domestic dogs. Am. Nat. 175, 753-758.

Castanheira, M.F., Herrera, M., Costas, B., Conceicao, L.E.C. and Martins, C.I.M. 2013. Can We Predict Personality in Fish? Searching for Consistency over Time and across Contexts. PLoS ONE 8, e62037.

Claridge, P.N. and Potter, I.C. 1984. Abundance, movements and size of gadoids (Teleostei) in the Severn Estuary. J. Mar. Biol. Ass. U.K. 64, 771-790.

Coleman, K. and Wilson, D.S. 1998. Shyness and boldness in pumpkinseed sunfish: individual differences are context-specific. Anim. Behav. 56, 927-936.

Costa, P.T., McCrae, R.R. 1980. Influence of extraversion and neuroticism on subjective well-being: happy and unhappy people. J. Pers. Soc. Psychol. 38(4), 668-678.

Crozier, W.R. 2001. Shyness, self-perception and reticence. In: Riding R.J. \& Rayner S.G. (Eds.), International perspectives on individual differences, vol2, Wesport, pp. 53-76.

Dahlbom, S.J., Lagman, D., Lundstedt-Enkel, K., Sundström, L.F., Winberg, S.,. 2011. Boldness predicts social status in zebrafish (Danio rerio). PLoS ONE 6, e23565.

Dando, P.R. and Demir, N. 1985. On the spawning and nursery grounds of bass, Dicentrarchus labrax, in the Plymouth area. J. Mar. Biol. Ass. U.K. 65, 159-168.

Dill, L.M. 1983. Adaptive Flexibility in the Foraging Behavior of Fishes. Can. J. Fish. Aquat. Sci. 40, 398-408. 
Di-Poï, C. 2008. Déterminisme de la structure sociale chez le bar juvénile Dicentrarchus labrax en conditions d'auto-nourrissage : Approches neuro-éthologique et physiologique. Thèse doc., Saint-Etienne, 257 pp.

Eriksson, C.A., Booth, D.J., Biro, P.A. 2010. Personality in two species of temperate damselfish. Mar. Ecol. Prog. Ser. 420, 273-276.

Ferrari, S., Benhaïm, D., Colchen, T., Chatain, B. and Bégout, M.-L. 2014. First links between self-feeding behaviour and personality traits in European seabass, Dicentrarchus labrax. Appl. Anim. Behav. 161, 131-141.

Ferrari, S., Millot, S., Leguay, D., Chatain, B. and Bégout, M.-L. 2015. Consistency in European seabass coping styles: A life-history approach. Appl. Anim. Behav. 167, 7488.

Fraser, D., Gilliam, J., JDaley, M., NLe, A., Skalski, G. 2001. Explaining leptokurtic movement distributions: intrapopulation variation inboldness and exploration. Am. Naturalist 158, 124-135.

Fricke, H. 1973. Individual partner recognition in fish: field studies on Amphiprion bicinctus. Naturwissenschaften 60, 204-205.

Godin, J.-G.J. and Dugatkin, L.A. 1996. Female mating preferences for bold males in the guppy, Poecilia reticulata. Proc. Natl. Acad. Sci. U. S. A., 10262-10267.

Gosling, S.D. 2001. From Mice to Men: What Can We Learn About Personality From Animal Research? Psychol. Bull. 127, 45-86.

Gosling, S.D. and John, O.P. 1999. Personality dimensions in nonhuman animals: A crossspecies review. Current Directions in Psychological Science 8, 69-75.

Griffiths, S. 1997. Preferences for familiar fish do not vary with predation. J. Fish Biol. 51, 489-495.

Griffiths, S.W. and Ward, A. 2007. Learned Recognition of Conspecifics. Blackwell Publishing Ltd, 139-165 pp.

Griffiths, S.W. 2003. Learned recognition of conspecifics by fishes. Fish and Fisheries 4, 256268.

Hamilton, W.D. 1971. Geometry for the selfish herd. J. Theor. Biol. 31, 295-311.

Helfman, G.S. 1984. School fidelity in fishes: The yellow perch pattern. Anim. Behav. 32, 663-672.

Hert, E. 1985. Individual recognition of helpers by the breeders in the cichlid fish Lamprologus brichardi (Poll, 1974). Zeitschrift fur Tierphysiologie 68, 313-325.

Hilborn, R. 1991. Modeling the stability of fish shools: exchange of individual fish between schools of skipjack tuna (Katsuwonus pelamis). Can. J. Fish. Aquat. Sci. 48, 10811091.

Hinde, R.A., Titmus, G., Easton, O., Tamplin, A. 1985. Incidence of friendship and behaviour to strong associates versus non associates in preschool. Child Development 56, 234-254.

Hoare, D., Ruxton, G.D., Godin, J.-G. and Krause, J. 2000. The social organization of freeranging fish shoals. Oikos 89, 546-554.

Kelley, D.F. 1988. The importance of estuaries for sea-bass Dicentrarchus labrax (L.). J. Fish Biol. 33(Suppl. A), 25-33.

Koolhaas, J.M. 2008. Coping style and immunity in animals: Making sense of individual variation. Brain, Behavior, and Immunity 22, 662-667.

Koolhaas, J.M., Korte, S.M., De Boer, S.F., Van Der Vegt, B.J., Van Reenen, C.G., Hopster, H., De Jong, I.C., Ruis, M.A.W. and Blokhuis, H.J. 1999. Coping styles in animals: current status in behavior and stress-physiology. Neurosci. Biobehav. Rev. 23, 925935. 
Krause, J., Godin, J.-G. and Brown, D. 1996. Phenotypic variability within and between fish shoals. Ecology 77, 1586-1591.

Krause, J. and Ruxton, G.D. 2002. Living in groups. Oxford University Press.

MacKenzie, S., Ribas, L., Pilarczyk, M., Capdevila, D.M., Kadri, S., Huntingford, F.A.,. 2009. Screening for coping style increases the power of gene expression studies. PLoS ONE 4, e5314.

Magurran, A.E. 1990. The inheritance and development of minnow anti-predator behaviour. Anim. Behav. 39, 834-842.

Maximino, C., de Brito, T.M., da Silva Batista, A.W., Herculano, A.M., Morato, S., Gouveia Jr, A. 2010. Measuring anxiety in zebrafish: A critical review. Behav. Brain Res. 214, 157-171.

Neuman, Y. 2014. Personality from a cognitive-biological perspective. Physics of Life Reviews 11, 650-686.

Orpwood, J.E., Magurran, A.E., Armstrong, J.D. and Griffiths, S.W. 2008. Minnows and the selfish herd: effects of predation risk on shoaling behaviour are dependent on habitat complexity. Anim. Behav. 76, 143-152.

Øverli, Ø., Sørensen, C. and Nilsson, G.E. 2006. Behavioral indicators of stress-coping style in rainbow trout: Do males and females react differently to novelty? Physiol. Behav. 87, 506-512.

Øverli, Ø., Korzan, W.J., Larson, E.T., Winberg, S., Lepage, O., Pottinger, T.G., Renner, K.J. and Summers, C.H. 2004. Behavioral and neuroendocrine correlates of displaced aggression in trout. Horm. Behav. 45, 324-329.

Peuhkuri, N., Ranta, E., Sanna-Kaisa, J. and Lindstrom, K. 1995. Schooling affects growth in the three-spined stickleback, Gasterosteus aculeatus. J. Fish Biol. 46, 221-226.

Pitcher, T.J. and Parrish, J.K. 1993. Functions of shoaling behaviour in teleosts. In Behaviour of Teleost Fishes (Pitcher, T. J., ed.), pp. 363-439. London: Chapman \& Hall.

Pöysä, H. 1994. Group foraging, distance to cover and vigilance in the teal, Anas crecca. Anim. Behav. 48, 921-928.

Réale, D. and Festa-Bianchet, M. 2003. Predator-induced natural selection on temperament in bighorn ewes. Anim. Behav. 65, 463-470.

Roberts, G. 1996. Why vigilance decreases as group size increases. Animal Behavior 51, 1077-1086.

Ruiz-Gomez, M.d.L., Huntingford, F.A., Øverli, Ø., Thörnqvist, P.-O., Höglund, E.,. 2011. Response to environmental change in rainbow trout selected for divergent stress coping styles. Physiol. Behav. 102, 317-322.

Seyfarth, R.M., Silk, J.B. and Cheney, D.L. 2012. Variation in personality and fitness in wild female baboons. Proceedings of the National Academy of Sciences 109, 16980-16985.

Sih, A., Bell, A. and Chadwick Johnson, J. 2004. Behavioral syndromes: an ecological and evolutionary overview. Trends Ecol. Evol. 19, 372-378.

Sneddon, L.U. 2003. The bold and the shy: individual differences in rainbow trout. J. Fish Biol. 62, 971-975.

Stirling, H.P. 1977. Growth, food utilization and effect of social interaction in the European bass Dicentrarchus labrax. Mar. Biol. 40, 173-184.

Svensson, P.A., Balrber, I. and Forsgren, E. 2000. Shoaling behaviour of the two-spotted goby. J. Fish Biol. 56, 1477-1487.

Verbeek, M.E.M., Drent, P.J. and Wiepkema, P.R. 1994. Consistent individual differences in early exploratory behaviour of male great tits. Anim. Behav. 48, 1113-1121.

Ward, A.J.W., Thomas, P., Hart, P.J.B. and Krause, J. 2004. Correlates of boldness in threespined sticklebacks (Gasterosteus aculeatus). Behavioural Ecology and Sociobiology 55, 561-568. 
583

584

585

586

587

588

589
Waas, J.R. and Colgan, P.W. 1994. Male sticklebacks can distinguish between familiar rivals on the basis of visual cues alone. Anim. Behav. 47, 7-13.

Wilson, D., Clark, A., Coleman, K. \& Dearstyne, T. 1994. Shyness and boldness in humans and other animals. Trends Ecol. Evol. 9, 442-446.

Zajonc, R.B. 1968. Attitudinal effects of mere exposure. J. Pers. Soc. Psychol. 9(2), 1-27. 


\section{$\underline{\text { Figure legends }}$}

Fig.1. Schematic representation and picture of the social interaction device and the virtual 595 zones defined for the video recording analysis.

(a) Schematic configuration of the device with the familiar congener placed on the left side. Dotted lines are transparent Plexiglas ${ }^{\circledR}$ walls, continuous lines are white opaque plastic. The bottom of the device is made of transparent Plexiglas ${ }^{\circledR}$. Virtual zones defined for the video recordings analysis are: Start-Fam and StartUnfam closed by a removable transparent wall where the fish is placed at the beginning of the experiment; Pre-Fam and Pre-Unfam: areas located after Start-Fam and Start-Unfam; Fam: the area located near the compartment where the familiar congener was placed; Unfam: the area located near the compartment where the unfamiliar congener was placed; 1 and 2: left and right separate compartments 608

Fig. 2. Scheme and dimensions of the open field apparatus

Fig. 3. Proportion of time spent (mean \pm SEM in \%) by fish in each zone of the familiarity 612 test device. Start-Fam and Start-UnFam: Start-Box in front of the familiar or the unfamiliar 613 congener, Pre-Fam and Pre-Unfam: Pre-Familiar and Pre-Unfamiliar zones, Fam: zone near 614 the familiar congener, UnFam: zone near the unfamiliar congener. Significant differences $(P$ $615<0.05$ ) between zones are shown by different letters above the bar (rank-based multiple 616 comparisons). 
Fig. 4. Proportion of time spent (mean \pm SEM in \%) by fish in each zone of the open field.

620 Significant differences $(P<0.05)$ between zones are shown by different letters above the bar

621 (rank-based multiple comparisons).

622

623

624

625

626 Fig. 5. Pearson's correlation between the proportion of time spent in the zone near the familiar

627 congener (Fam) in the familiarity test and the first principal component scores using Principal

628 Components Analysis (PC1) in the open field test (OFT), $r=-0.41, \mathrm{~N}=30, p=0.04$.

629 Equation for the best linear fit is: $y=-7.5195 x+25.8$.

630

631

632

633

634 

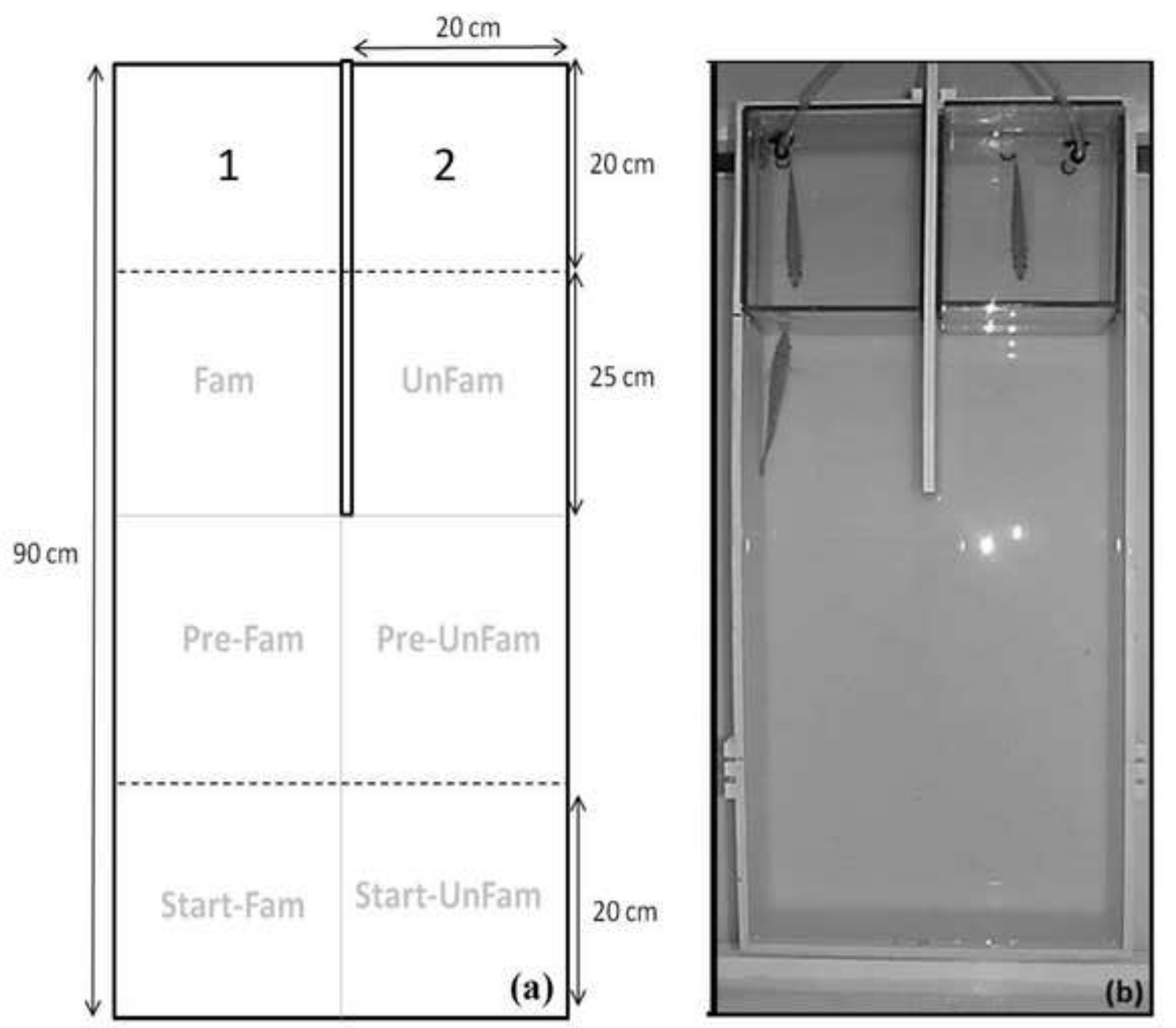


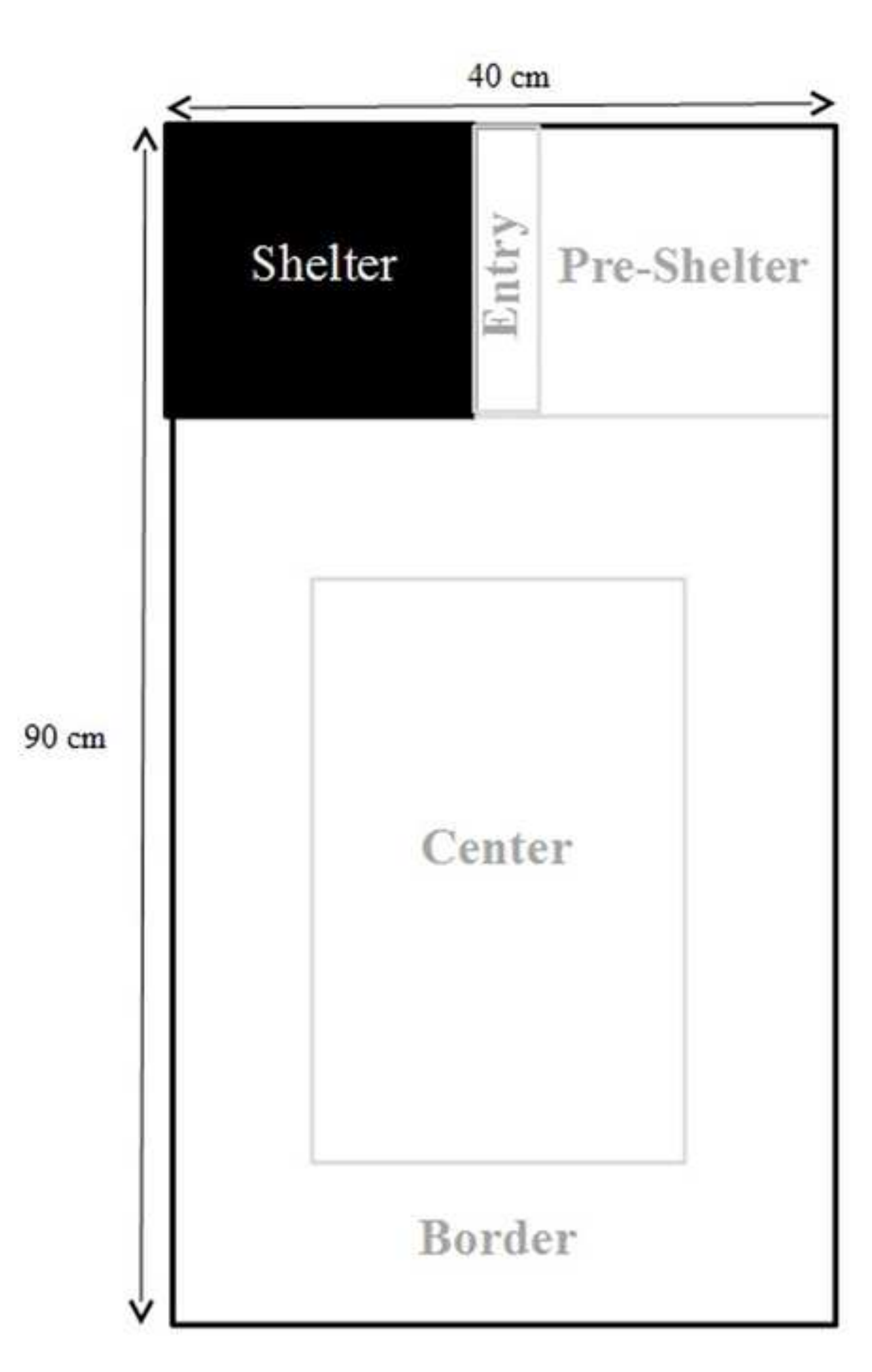

$40 \mathrm{~cm}$

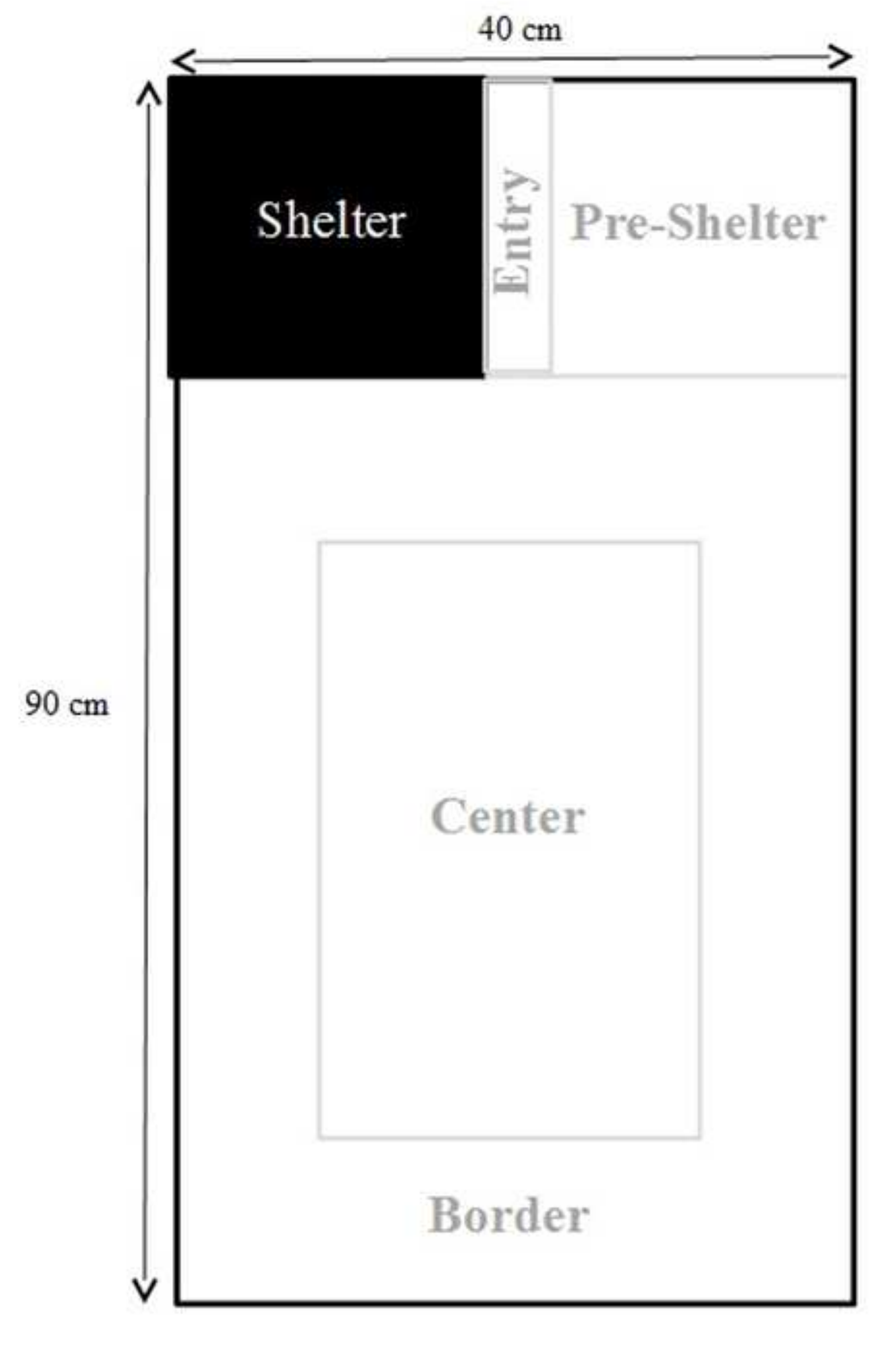

ACCEPTED MANUSCRIPT

-
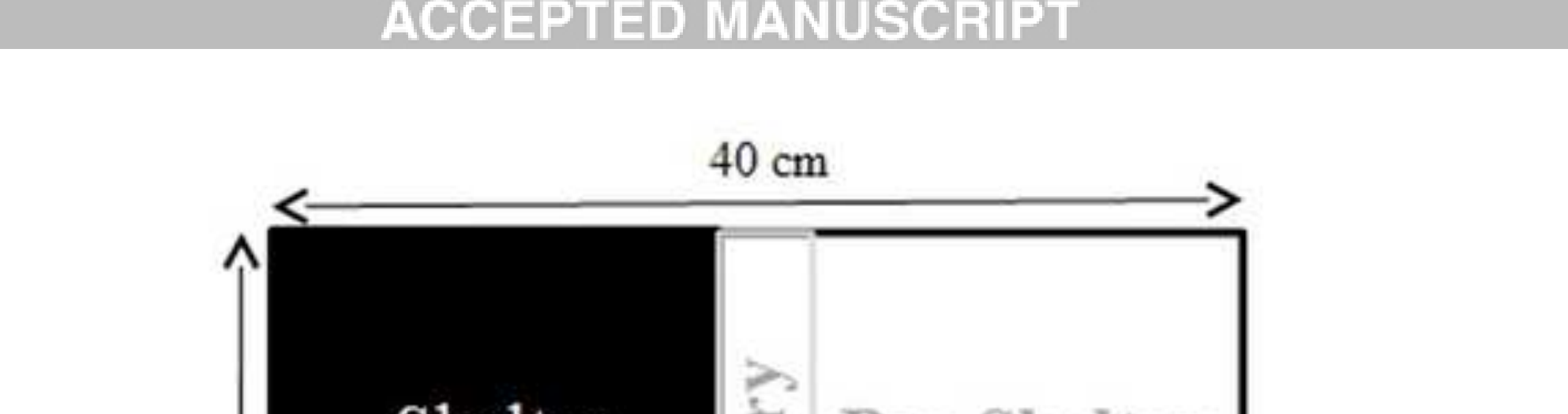


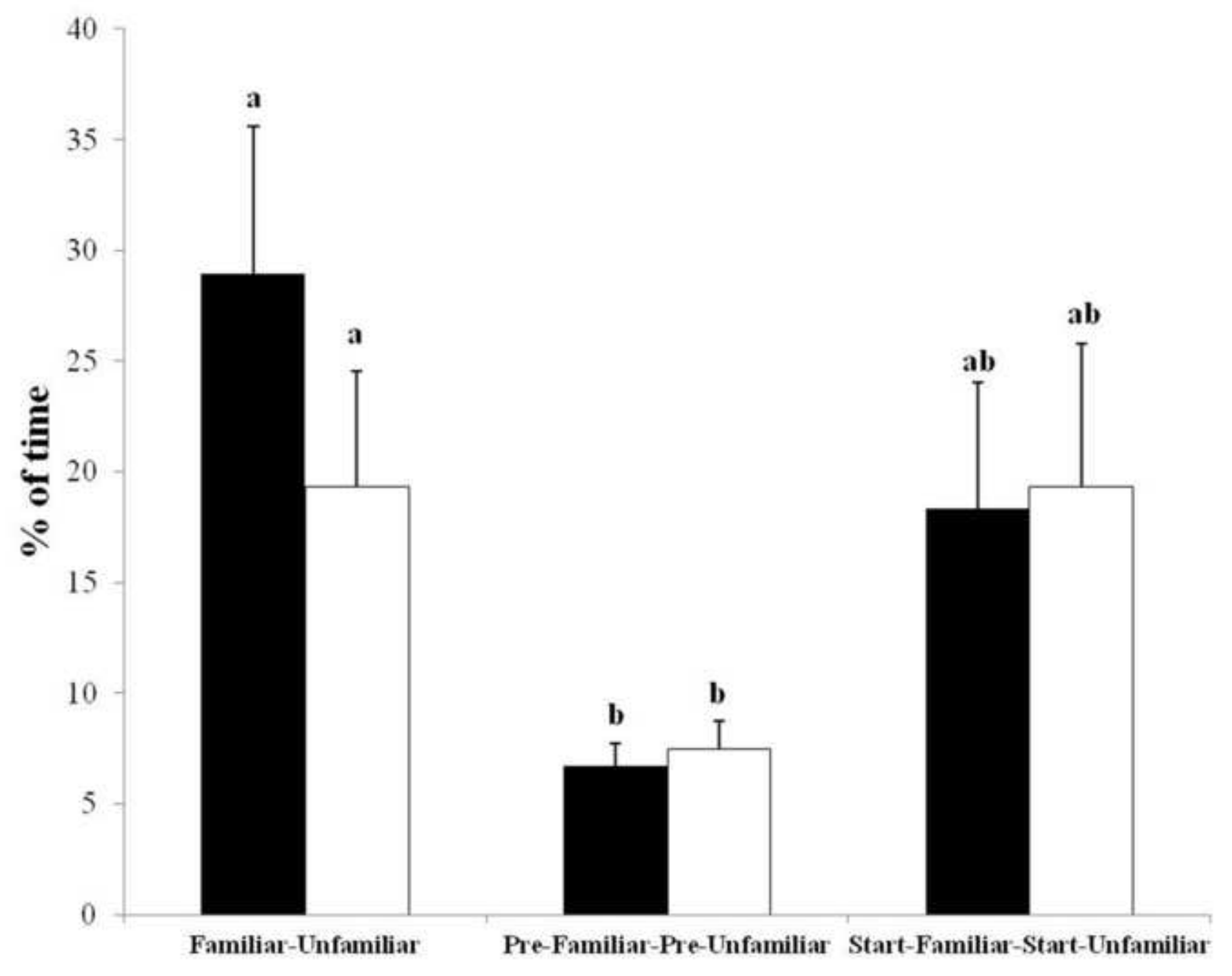




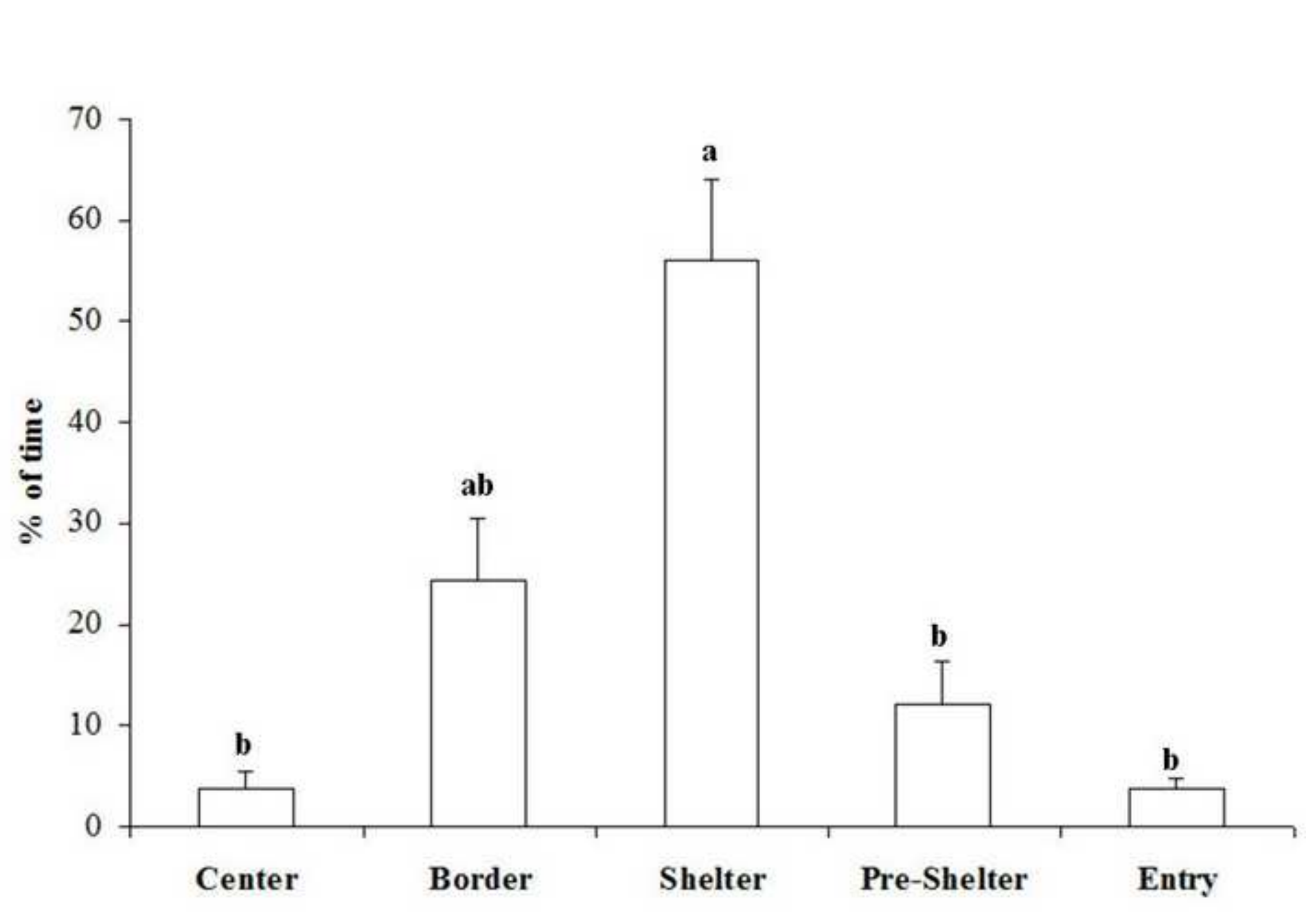




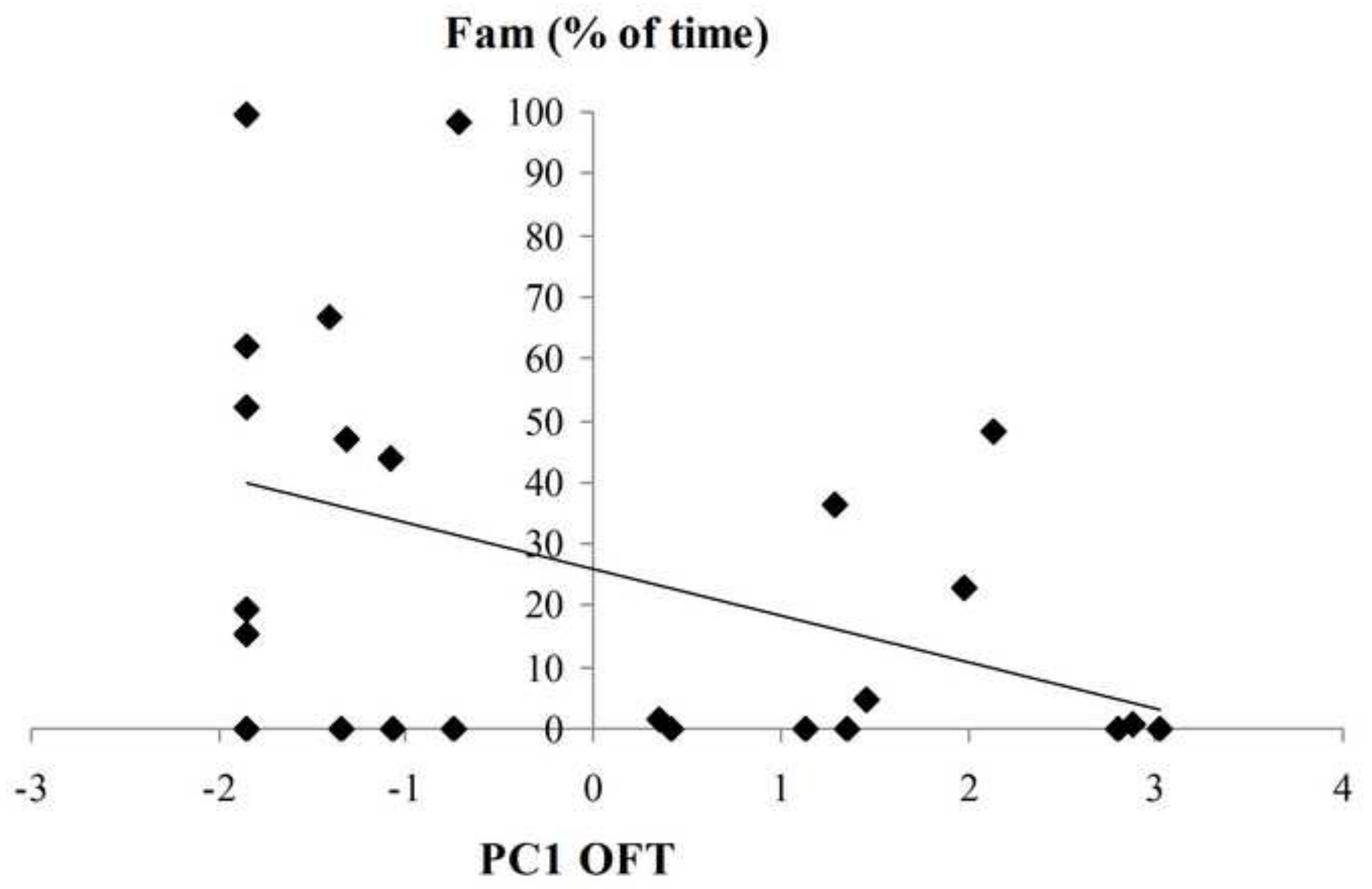

